\title{
Canaga Oil
}

National Cancer Institute

\section{Source}

National Cancer Institute. Canaga Oil. NCI Thesaurus. Code C107276.

The essential oil of Cananga odorata. Canang a oil is used primarily in aromatherapy preparations. 